\title{
PENINGKATAN KUANTITAS DAN KUALITAS USAHA KOPI BUBUK DI DESA PERMU KECAMATAN KEPAHIANG KABUPATEN KEPAHIANG
}

\section{QUANTITY AND QUALITY IMPROVEMENT OF COFFEE BUSINESS IN PERMU VILLAGE KEPAHIANG}

\author{
Oleh: \\ Alnopri, Prasetyo, dan Yessi Rosalina \\ Fakultas Pertanian Universitas Bengkulu \\ Alnopri_62@yahoo.co.id.
}

\begin{abstract}
Community service activities have been carried out in the Permu Village, Kepahiang Subdistrict, Kepahiang District. The target group is the group of mothers who take shelter Permu village in the "Tik Kerto". The purpose of this activity is to increase the number and improve the quality of coffee of Permu Village. The activities carried out by the method of illumination and field practice, transfer of technology, and promotion of products. Results show that a group of mothers who take the activities of in the village Permu Tik Kerto group are very enthusiastic and improving the quantity and quality of coffee products of Permu Village. Technology transfer processing using the ground coffee roaster machine is responded well and the quality of the resulting coffee powder are in accordance with SNI 01-3542-2004, the national standard of coffee. The conclusion of this activity is the formation of industry groups Tik Kerto coffee, coffee quality after transfer of technology is better than before, Permu Village coffee product of group of mothers Tik Kerto is improved. Suggestions for next years, implementation of the PPM complement of the activities carry out infrastructure and facilities for the production of ground coffee of Permu Village.
\end{abstract}

Keywords: Coffee, Quantity and Quality Improvement, Permu Village

\section{PENDAHULUAN}

Percaturan kopi dunia menunjukkan bahwa provinsi Bengkulu, Lampung dan Sumatera Selatan merupakan daerah penghasil kopi robusta utama di Indonesia. Berdasarkan fenomena tersebut, maka ketiga provinsi menyandang predikat sebagai daerah segitiga kopi (coffee triangle). Bappeda Provinsi Bengkulu (2010) menginformasikan bahwa provinsi Bengkulu mempunyai luas lahan kopi 99.704,00 hektar dengan produksi kopi Robusta 58.252,7 ton dan kopi Arabika 3,164 ton. Provinsi Sumatera Selatan mempunyai luas lahan kopi 220.606 hektar dengan produksi kopi Robusta 149.945 ton. Provinsi Lampung mempunyai luas lahan kopi 164.006 hektar dengan produksi kopi Robusta 140.945 ton dan Arabika 37 ton. Provinsi Bengkulu secara administrasi terdiri 
dari 9 (sembilan) kabupaten dan 1 (satu) kota, salah satu kabupaten penghasil kopi utama adalah kabupaten Kepahiang.

Kabupaten Kepahiang terbentuk pada tanggal 7 Januari 2004 berdasarkan Undangundang nomor 39 tahun 2003 tentang pembentukan Kabupaten Lebong dan Kabupaten Kepahiang Provinsi Bengkulu. Kabupaten Kepahiang merupakan kabupaten pemekaran dari kabupaten induk Kabupaten Rejang Lebong. Kabupaten Kepahiang mempunyai luas wilayah 66.500 hektar.

Kabupaten Kepahiang merupakan penghasil utama kopi di provinsi Bengkulu dan ditetapkan sebagai kawasan sentra produksi (KSP) kopi. Sentra produksi terdiri dari kecamatan Seberang Musi dan Kabawetan, kawasan industri adalah kecamatan Tebat Karai, dan kecamatan Kepahiang mempunyai peran sebagai kawasan pengolahan dan pemasaran. Pemasaran produk diharapkan dalam bentuk produk antara (intermediate product) dan produk jadi (final product).

Desa Permu merupakan sebuah desa di kecamatan Kepahiang yang terletak pada jalan utama antara Kota Kepahiang dan Kota Pagar Alam Provinsi Sumatera Selatan. Desa Permu terdiri dari $261 \mathrm{KK}$ dengan mata pencaharian utama sebagai petani yakni sebesar 90\% dengan komoditas utama pertanian tanaman pangan dan perkebunan, yakni tanaman kopi. Usaha pengolahan biji kopi di Desa Permu adalah pengolahan kopi biji menjadi kopi bubuk dan digunakan untuk keperluan rumah tangga sendiri. Aktivitas pengolahan industri rumah tangga tersebut adalah kegiatan penyangraian, penggilingan bubuk kopi, dan pengepakan. Aktivitas penyangraian dilakukan secara sederhana dengan alat kuali dengan bahan bakar dari kayu. Penggilingan dilakukan dengan menggunakan mesin giling (Alnopri, dkk., 2013).

Mitra usaha kopi bubuk di Desa Permu kabupaten Kepahiang adalah Ibu-ibu PKK Desa Permu yang beranggotakan 18 orang. Hasil penelitian dari PPM yang dilaksanakan pada tahun 2013 menunjukkan bahwa antusias mitra usaha sangat tinggi untuk mengembangkan usaha kopi bubuk. Hal ini ditunjukkan dari animo anggota kelompok dalam kegiatan produksi, pemasaran, dan upaya menata produksi dengan cara membeli kuali untuk alat sangrai.

Permasalahan yang dihadapi oleh mitra usaha kopi bubuk Desa Permu adalah sebagai berikut: Manajemen Organisasi yang belum efektif berjalan, Proses pembubukan belum memenuhi standar mutu, Kemasan masih sangat sederhana, dan Pemasaran hanya pada pasar setempat.

Komoditas kopi wajib diadakan pengujian mutu agar dapat dikeluarkan sertifikat mutu. Ketentuan tersebut merupakan syarat mutlak, karena komoditas kopi wajib memenuhi standar perdagangan yang ditetapkan oleh Menteri Perdagangan dengan cara menerbitkan Surat Pernyataan Mutu dan Sertifikat Mutu. Surat pernyataan mutu merupakan surat pernyataan dari pihak eksportir, bahwa komoditinya memenuhi standar perdagangan. Sertifikat mutu merupakan surat pernyataan dari Laboratorium penguji Mutu, bahwa komoditinya memenuhi standar perdagangan (Alnopri, 2005). 
Biji kopi sebagai komoditas ekspor telah memiliki standar nasional mutu biji kopi. Tujuan standarisasi adalah untuk menjaga citra mutu kopi Indonesia yang berkualitas baik dan juga untuk memenuhi persyaratan ekspor. Kopi bubuk Indonesia telah mempunyai standar nasional yang dikeluarkan oleh Badan Standar Nasional dengan nomor SNI 013542-2004 (Badan Standar Nasional, 2004).

Proses penyangraian terdiri dari beberapa tahapan, yakni persiapan biji beras (green bean), proses penyangraian, pendinginan, penghalusan, penyimpanan sementara, dan pengemasan. Aroma dan cita rasa kopi sebelum disangrai tersimpan dalam biji kopi, dan setelah disangrai aroma dan cita rasa kopi akan dapat dirasakan dan dinikmati oleh konsumen peminum seduhan kopi (Panggabean, 2011).

Proses penyangraian merupakan tahapan pembentukan aroma dan cita rasa khas kopi, dengn perlakuan panas. Proses sangrai menggunakan mesin sangrai tipe silinder berputar. Silinder sangrai dapat digerakkan dengan motor listrik atau motor bakar sedangkan sebagai sumber panas adalah kompor minyak tanah atau gas. Kapasitas mesin sangrai antara 10 sampai $40 \mathrm{~kg}$ per batch tergantung ukuran diameter silindernya (Budiman, 2012).

Proses sangrai diawali dengan penguapan air yang ada di dalam biji kopi dengan memanfaatkan panas yang tersedia dari kompor dan kemudian diikuti dengan reaksi pirolisis. Reaksi pirolisis merupakan rekasi dekomposisi senyawa hidrokarbon antara lain karbohidrat, hemislulose dan selulosa yang ada dalam biji kopi. Reaksi ini umumnya terjadi setelah suhu sangrai di atas $180^{\circ} \mathrm{C}$. Secara kimiawi proses ini ditandai dengan evolusi gas $\mathrm{CO}_{2}$ dalam jumlah banyak dari ruang sangrai berwarna putih. Secara fisik, pirolisis ditandai dengan perubahan warna biji kopi menjadi kecoklatan. Salah satu tolok ukur proses penyangraian adalah derajad sangrai yang dilihat dari perubahan warna biji kopi yang sedang disangrai yang diambil dari dalam silinder sudah mendekat warna sampel standar.

Sesudah proses penyangraian, biji kopi hasil sangrai dimasukkan ke dalam bak pendingin, agar proses sangrai tidak berlanjut. Selama pendinginan, biji kopi sangrai diaduk agar proses sangrai menjadi rata dan tidak berlanjut. Untuk bak pendingin yang dilengapi dengan kipas mekanis, sisa kulit ari yang terlepas akan terhisap sehingga biji kopi sangrai menjadi lebih bersih.

Biji kopi sangrai dihaluskan dengan alat penghalus (grinder) sampai diperoleh butiran kopi bubuk dengan kehalusan tertentu. Tujuannya adalah suaya kopi mudah diseduh dan memberikan sensasi rasa dan aroma yang lebih optimal. Mekanisasi penghalusan terjadi dengan adanya geseran antara permukaan biji kopi sangrai dengan permukaan piringan dan sesame biji kopi sangrai. Kopi bubuk ukuran halus diperoleh dari ayakan dengan ukuran lubang 200 mesh, sedangkan untuk ukuran bubuk medium digunakan ayakan 120 mesh.

Proses gesekan yang sangat sensitive akan menyebabkan panas di bagian silindernya dan akan menyebabkan aroma kopi bubuk berkurang. Untuk menghindari hal tersebut, maka mesin penghalus dihentikan dan didinginkan sejenak apabila suhu kopi bubuk di dalam kotak penampung meningkat secara tidak wajar.

Rendemen bubuk adalah perbandingan antara berat kopi bubuk dengan berat biji kopi beras yang diproses. Rendemen bubuk akan semakin rendah pada derajad sangrai makin gelap. Rendemen tertinggi yaitu $81 \%$ diperoleh dengan derajad sangrai ringan, dan terrendah yaitu $76 \%$ dengan derajad sangrai gelap. Rendemen juga dipengaruhi oleh susut berat biji kopi selama penyangraian. 
Makin tinggi kadar air bji dan makin lama waktu penyangraian akan menyebabkan rendemen menjadi lebih kecil.

Kemasan adalah semua bahan yang digunakan untuk mewadahi, membungkus atau menyimpan bahan pangan. Kemasan merupakan "identitas" makanan yang dikemas. Kemasan dapat mempengruhi mutu produk yang dikemas. Tujuan pengemasan adalah untuk mempertahankan aroma dan cita rasa kopi bubuk selama didistribusikan ke konsumen dan selama dijajakan di toko, di pasar tradisional dan pasar swalayan. Kemasan harus dapat menarik minat pembelai kopi bubuk melalui rancangan gambar, warna dan tulisan yang ada diluarnya. Tampilan yang paling baik adalah model cetak. Untuk usaha pemula kemasan model sablon, asalkan digarap dengan baik akan menghasilkan tampilan kemasan yang menarik (Tim Karya Tani Mandiri, 2010).

Jenis kemasan untuk kopi bubuk terdiri dari plastik transparan dan aluminium foil. Masing-masing jenis bahan mempunyai keunggulan dan kelemahan, baik dari aspek daya simpan, kepraktisan, dan harga. Proses pengemasan secara manual dilakukan dalam tiga tahapan, yaitu memasukkan kopi bubuk ke dalam kemasan, menimbang kemasan, dan menutup kemasan. Ketiga tahapan dilakukan oleh tiga operator berurutan. Labeling dan tanggal kadaluwarasa dilakukan stelah seluruh tahapan proses pengemasan selesai.

Peluang pasar merupakan suatu peluang dari produsen untuk menjual produknya dengan mendapatkan keuntungan. Pelaku pemasaran tidak semuanya mampu memanfaatkan peluang pasar tersebut. Oleh karena itu perlu diterapkan strategi pemasaran. Untuk dapat memasuki suatu pasar, maka perlu dilakukan telaah beberapa hal, yakni 1) mengetahui sejauhmana kemampuan produk yang akan dipasarkan, 2) mengetahui jumlah permintaan pasar dan standar mutu produk, dan 3) mengetahui selera konsumen.

Untuk menembus peluang pasar tersebut, maka perlu dilakukan promosi produk. Promosi dapat dilakukan dengan berbagai cara, antara lain 1) promosi secara langsung (door to door promotion), 2) mengikuti event-event promosi yang dilakukan pihak tertentu, 3) membuat kegiatan promosi, contoh Hari Kopi (coffee Day).

Tujuan dari kegiatan ini adalah untuk meningkatkan jumlah produksi kopi bubuk kelompok "Tik Kerto" ibu-ibu Desa Permu, meningkatkan kualitas kopi bubuk Desa Permu produk kelompok "Tik Kerto" ibu-ibu Desa Permu, dan memperluas jaringan pemasaran kopi bubuk Desa Permu. Manfaat dari kegiatan ini adalah Produksi kopi bubuk kelompok ibu-ibu Desa Permu akan meningkat, sehingga akan meningkatkan pendapatan anggota kelompok dan kualitas kopi bubuk kelompok ibu-ibu Desa Permu akan meningkat, sehingga akan menghasilkan mutu kopi bubuk yang baik dan siap menembus pasar di kawasan Kabupaten Kepahiang.

\section{METODE PENGABDIAN}

Kelompok usaha kopi bubuk Desa Permu merupakan ibu-ibu PKK Desa Permu. Kelompok ini belum mempunyai aktivitas bisnis, sehingga perlu ditularkan manajemen bisnis yang berorientasi keuntungan (Profit oriented). Kegiatan dilakukan dengan cara penyuluhan dan mengadakan rapat-rapat anggota kelompok.

Untuk menata kelompok industri kopi bubuk Desa Permu Kecamatan Kepahiang kabupaten Kepahiang dilakukan dengan cara rapat anggota dan didampingi oleh Kepala 
Desa dan Tim Pengabdian pada Masyarakat Universitas Bengkulu (PPM Unib). Pada rapat anggota tersebut dilakukan pengisian struktur pengurus yang berbasiskan organisasi bisnis. Kemudian juga akan dilakukan rapat pengurus untuk mengatur permodalan dan pembagian keuntungan usaha kopi bubuk.

Peningkatan kuantitas produk kopi bubuk Desa Permu Kecamatan Kepahiang kabupaten Kepahiang sangat ditentukan oleh ketersediaan bahan baku berupa kopi biji (green bean). Bahan baku yang baik akan sangaat berkorelasi dengan teknologi budidaya tanaman kopi. Oleh karena itu, penyuluhan dilakukan dengan materi tentang budidaya kopi, teknologi penyambungan (grafting) dan pentingnya petik merah secara selektif.

Kegiatan penyuluhan dilakukan di balai Desa Permu terhadap ibu-ibu anggota kelompok. Kegiatan kunjungan peninjauan ke kebun kopi produktif dilakukan oleh pekebun kopi dan pembina. Agenda di kebun adalah diskusi tentang budidaya tanaman kopi dan teknologi penyambungan.

Peningkatan kualitas kopi bubuk sangat ditentukan oleh metode penyangraian. Oleh karena itu, maka penyangraian dengan menggunakan kuali dengan bahan pemanas kayu api diganti dengan menggunakan mesin sangrai (roaster) dengan bahan pemanas kompor gas. Mesin sangrai yang digunakan adalah mesin sangrai dengan kapasitas $15 \mathrm{~kg}$ dengan mesin penggerak Honda dan alat pemanas kompor gas.

Penataan kemasan dilakukan dengan mendesign logo kemasan berbasiskan alam kawasan Tik Kerto dengan warna yang menarik dan kata-kata yang berorientasi bisnis.

Penetrasi pemasaran dilakukan dengan cara ekspansi ke pasar-pasar tradisional di Kabupaten Kepahiang dengan cara menitipkan produk pada warungwarung dan mengganti produk pada waktu-waktu tertentu.

Promosi produk kopi bubuk Desa Permu dilakukan dengan cara mengadakan hari kopi (coffee day). Acara ini dilakukan di selingkung Universitas Bengkulu, dengan melibatkan dosen dan mahasiswa sebagai peserta kegiatan tersebut. Materi acara adalah mensosialisasikan kopi bubuk Desa Permu dan meminta umpan balik untuk perbaikan industri kopi bubuk di kemudian hari.

Untuk menguji mutu alih teknologi yang dilaksanakan pada kegiatan pengabdian pada masyarakat, maka diadakan pengujian tentang rendemen hasil (rasio kopi biji dan kopi gelondong basah), rendemen bubuk (rasio kopi bubuk dan kopi pasar0, dan mutu kopi sangrai. 


\section{HASIL DAN PEMBAHASAN}

\section{Penataan Manajemen Kelompok}

Langkah awal kegiatan pengabdian pada masyarakat di Desa Permu adalah melakukan koordinasi dengan Kepala Desa. Kegiatan dilakukan di Balai Desa Permu. Koordinasi dengan Kepala Desa disajikan pada Gambar 1.
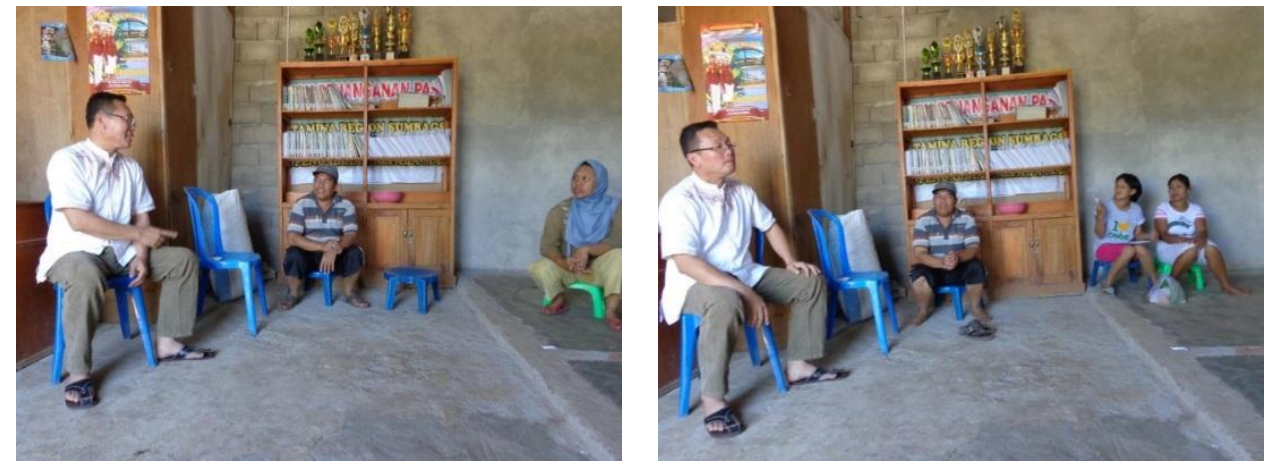

Gambar 1. Koordinasi dengan Kepala Desa Permu

Kepala Desa Permu sangat antusias menyambut kegitan pengabdian masyarakat di Desa Permu yang merupakan kelanjutan dengan kegiatan Pengabdian Pada Masyarakat (PPM) PENERAPAN IPTEKS, dengan judul Meraih Nilai Tambahan Produk Kopi yang Hilang Berbasis Intermediate Product di Desa Permu Kabupaten Kepahiang (Alnopri, dkk., 2013).

Penataan kelompok ibu-ibu PKK Desa Permu untuk melakukan kegiatan industri kopi bubuk dibimbing oleh Tim PPM UNIB. Kegiatan rapat Kelompok disajikan pada Gambar 2. Hasil kesepakatan kelompok ibu-ibu Desa Permu sepakat mengubah nama menjadi kelompok "Tik Kerto" ibu-ibu Desa Permu. Tik Kerto adalah mata air yang merupakan sumber air Desa Permu. Harapan ibu-ibu anggota kelompok dengan menggunakan nama tersebut akan dapat menjadi sumber pendapatan tambahan bagi keluarga dengan kegiatan industri kopi bubuk.

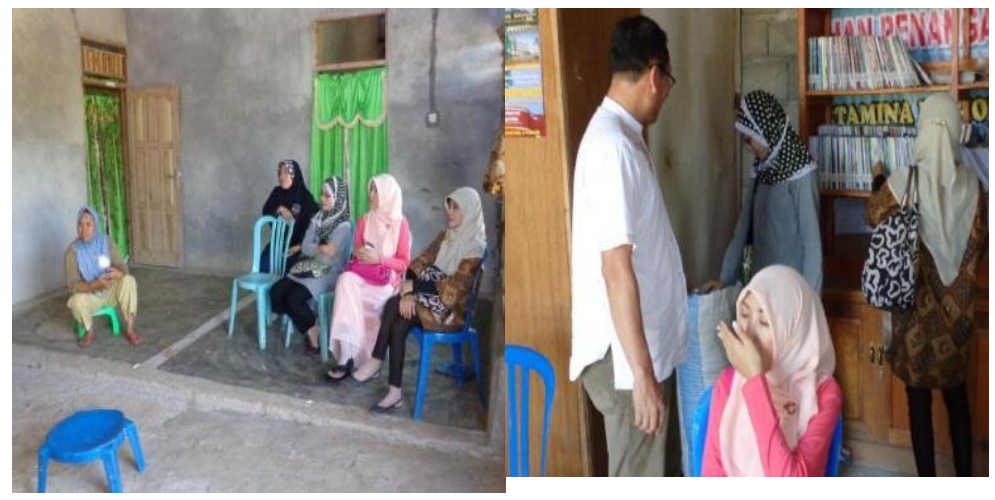

Gambar 2. Rapat Kelompok Dibimbing oleh Tim PPM UNIB 
Hasil rapat anggota kelompok ibu-ibu yang bernaung pada kelompok Tik Kerto dengan agenda penataan struktur organisasi yang berorientasi bisni kopi bubuk adalah sebagai berikut:

Ketua: Farida, Sekretrais: Herlina, Bendahara: Leti, Ketua Unit Produksi: Reni Elliza, dan Ketua Unit Pemasaran: Fatmawati.

Untuk merangsang aktivitas kelompok industri kopi bubuk Desa Permu, maka dilakukan stimulant berupa pemberian modal awal. Modal awal untuk membeli kopi biji bermutu diserahkan melalui Kepala Desa. Kepala Desa Permu selanjutnya menyerahkan bantuan modal tersebut kepada ketua kelompok.

\section{Upaya Peningkatan Kuantitas Produk}

Upaya meningkatkan kuantitas produk kopi bubuk Desa Permu dimulai dengan melakukan penyuluhan dengan materi budidaya tanaman kopi, petik merah selektif, dan Teknologi Grafting. Kunjungan ke kebun produksi dilakukan oleh tim PPM UNIB dan pekebun kopi Desa Permu. Kegiatan kunjungan ke kebun kopi produktif disajikan pada Gambar 3.
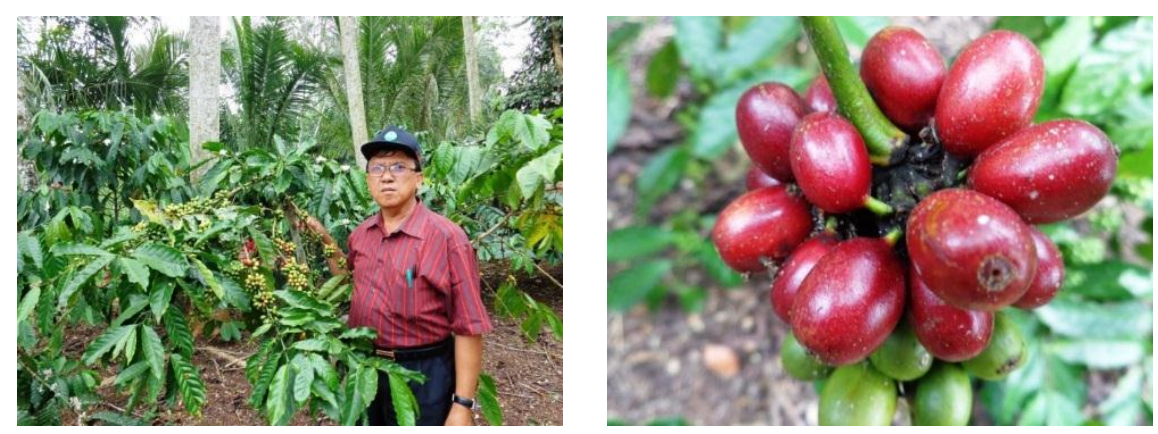

Gambar 3. Tim PPPM UNIB dan Kopi Merah Siap Petik

Kunjungan ke kebun kopi produktif di Desa Permu Kabupaten Kepahiang menunjukkan bahwa kebun kopi cukup baik. Teknologi pemangkasan terutama pemangkasan bentuk dan pemangkasan produktif sudah dilakukan dengan baik oleh pekebun. Buah kopi di kebun sudah banyak dalam kondisi berwarna merah, sehingga teknologi petik merah secara selektif akan dapat dilaksanakan.

Komentar pekebun terhadap teknologi petik merah adalah sudah mengetahui tentang manfaat dan keunggulan petik merah secara selektif. Akan tetapi teknologi tersebut masih sulit diadobsi, dengan alasan tuntutan ekonomi dan faktor non teknis lainnya. Hal inilah yang menyebabkan teknologi petik merah secara selektif belum dilakukan oleh pekebun kopi di kawasan Desa Permu.

Teknologi penyambungan (grafting) sudah sangat familier di kalangan pekebun kopi Desa Permu. Teknologi penyambungan sudah dilakukan oleh pekebun dengan istilah kopi setek. Kopi hasil penyambungan di Desa Permu menunjukkan suatu fenomena baru yang unik dan menarik. Pohon kopi hasil penyambungan akan berbuah setiap saat, sehingga pekebun dapat memetik kopi setiap bulan. Hal ini memberikan indikasi bahwa suplai 
bahan baku untuk industry kopi bubuk berupa biji kopi akan tersedia setiap waktu. Apabila suplai bahan baku tidak dapat dipenuhi oleh kebun kopi di sekitar Desa Permu, maka bahan baku dapat dibeli dari kawasan Sengkuang yang mempunyai ketinggian di atas 1.000 meter dari permukaan laut. Pada Gambar 4 disajikan kebun kopi hasil teknologi penyambungan.
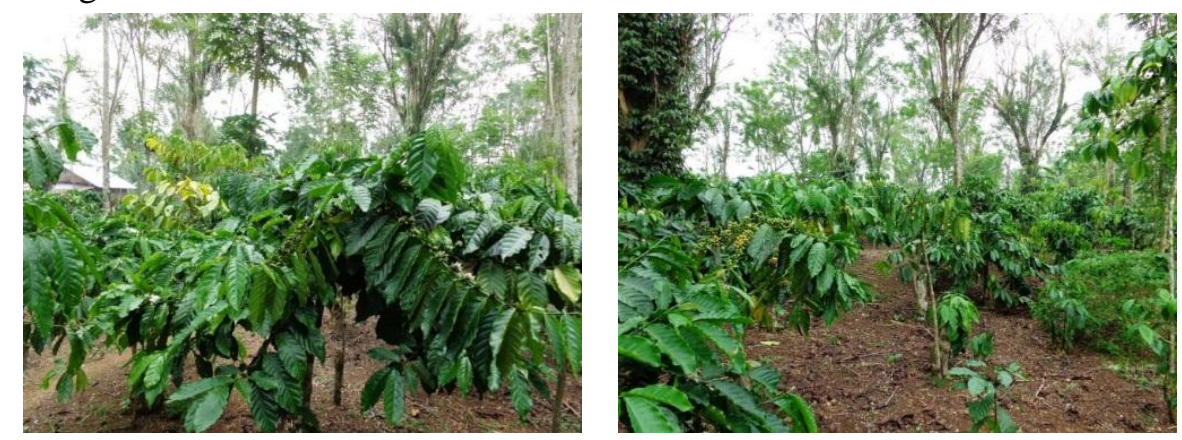

Gambar 4. Kopi Robusta Hasil Teknologi Grafting

Kopi gelondong basah hasil pemetikan selanjutnya diolah dengan sistem kering. Tahapan pegolahan adalah penjemuran dan penggilingan, penjemuran dilakukan pada tikar jemur sehingga dihasilkan kopi gelondong kering. Penjemuran dilakukan 7 sampai 10 hari tergantung intensitas sinar matahari. Kopi gelondong kering ditumbuk dengan mesin (huller) dan akan menghasilkan kopi biji (green bean).

\section{Upaya Peningkatan Kualitas Produk Kopi Bubuk}

Produksi Kopi Bubuk Desa Permu pada awal kegiatan pengabdian ini masih dilakukan secara tradisional, yakni penyangraian dilakukan menggunakan kuali dan bahan bakar kayu api. Hal ini masih dilakukan, karena mesin sangrai (roaster) masih dipesan. Teknologi penyangraian secara tradisonal tersebut mempunyai kelemahan yakni tidak dapat mengontrol panas yang dihasilkan oleh kayu bakar.

Proses produksi kopi bubuk adalah penyangraian menggunakan kuali, penghalusan menggunakan mesin pembubuk (grinder) dengan system sewa Rp. 2.000,- per kilogram, dan pengemasan dengan bahan plastik transparan. Proses produksi disajikan pada Gambar 5 dan Gambar 6.
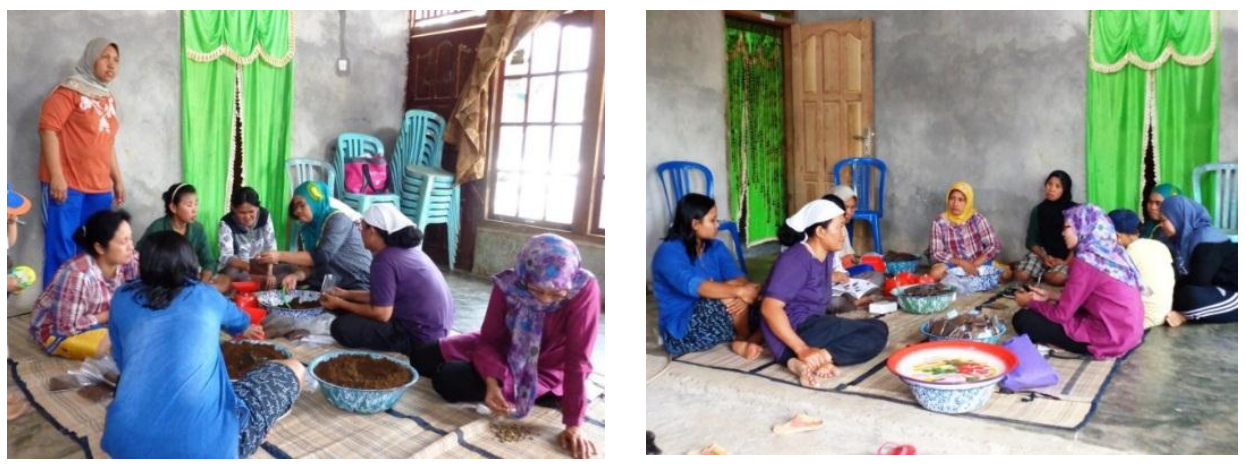

Gambar 5. Proses Produksi Kopi Bubuk Desa Permu 

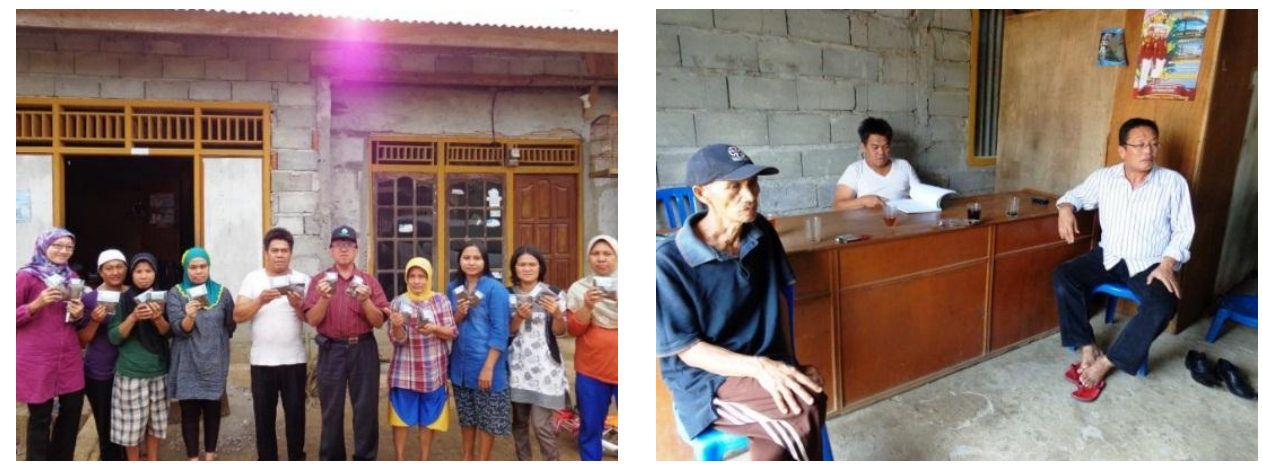

Gambar 6. Hasil Produksi Kopi Bubuk Siap Dipasarkan

Kopi bubuk yang dihasilkan mempunyai rendemen bubuk sebesar $73.33 \%$ dan warna kopi bubuk coklat kehitaman. Hasil ini memberikan indikasi bahwa bahan baku berupa kopi biji cukup baik dan proses penyangraian masih memerlukan perbaikan teknologi. Oleh karena itu teknologi penyangraian dengan menggunakan roaster perlu ditularkan kepada kelompok ibu-ibu produsen kopi bubuk Desa Permu.

Perbaikan teknologi penyangraian dilakukan dengan cara menggunakan mesin sangrai (roaster) dengan volume $15 \mathrm{~kg}$ kopi biji. Alih teknologi penyangraian dengan menggunakan mesin sangrai (roaster) dilakukan dengan menggunakan bahan baku kopi biji sebanyak $10 \mathrm{~kg}$. Proses alih teknologi disajikan pada Gambar 7. Hasil alih teknologi penyangrai disajikan pada Gambar 8.
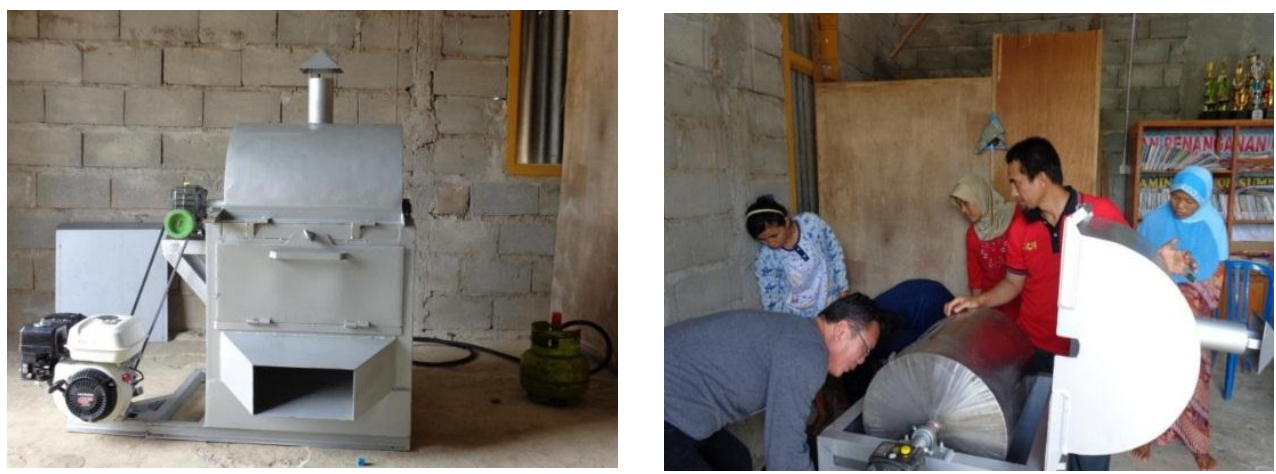

Gambar 7. Alih Teknologi Penyangraian Menggunakan Roaster

Alih teknologi dengan menggunakan mesin sangrai dengan antusias dan sangat mudah dikuasai oleh kelompok industry bubuk kopi Tik Kerto Desa Permu. Rendemen bubuk yang dihasilkan adalah $83,10 \%$. Rendemen yang dihasilkan tersebut dikategorikan pada aktivitas derajat sangrai ringan dengan hasil kopi sangrai berwarna dominan coklat (Budiman, 2012). 

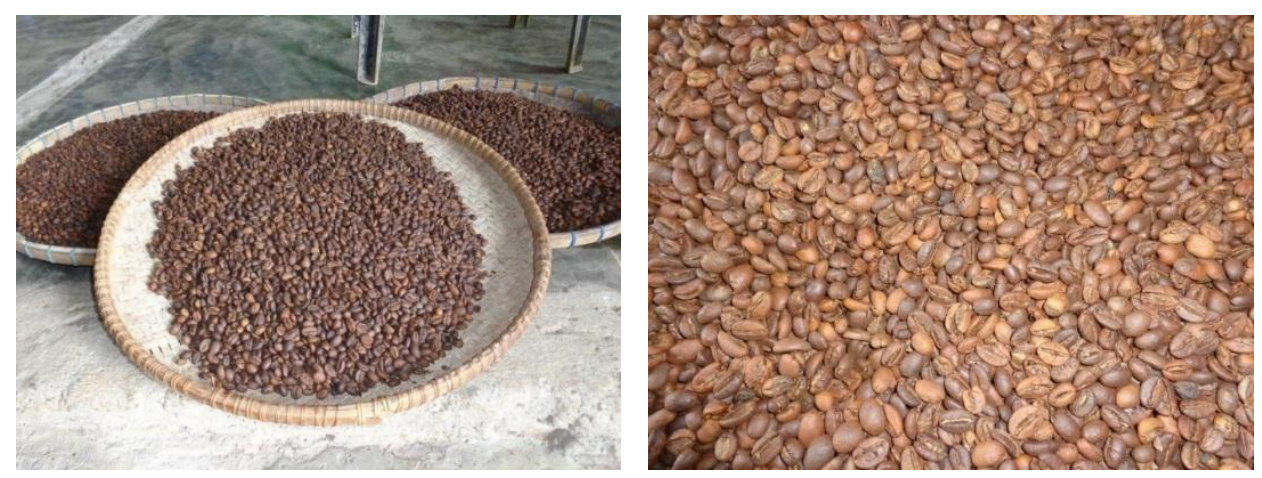

Gambar 8. Biji Kopi Sangrai Hasil Alih Teknologi

\section{Hari Kopi (Coffee Day)}

Pelaksanaan promosi dalam bentuk Hari Kopi (coffee day) dilaksanakan di ruang Rapat Fakultas Pertanian Universitas Bengkulu. Peserta terdiri dari pimpinan fakultas (Dekan, Wakil Dekan bidang Akademik, Wakil Dekan bidang Kemahasiswaan, dan Ketua Jurusan Budidaya Pertanian), dosen selingkung Fakultas Pertanian UNIB, dan Mahasiswa.

Kegiatan hari kopi yang diprakarsai oleh Tim PPM UNIB mendapat sambutan dan apresiasi dari Dekan Fakultas Pertanian UNIB dan peserta. Kegiatan seperti ini diharapkan dapat dijadikan model untuk menjalin silahturahmi antar sivitas akademika dan pada tahun 2016 komoditas kopi akan dijadikan motor penggerak kegiatan penelitian dan pengabdian selingkung Fakultas Pertanian UNIB.

Terkait dengan pengembangan untuk industri kopi bubuk Desa Permu, peserta hari kopi memberikan saran-saran yang sangat konstruktif. Kualitas kopi bubuk Desa Permu masih perlu ditingkatkan, yakni dengan membuat berbagai tingkat sangrai. Tingkat sangrai kopi terdiri dari tiga tingkat, yakni tingkat sangrai ringan (warna coklat muda), tingkat sangrai medium (warna coklat agak gelap), dan tingkat sangrai gelap (warna coklat tua cenderung hitam). Tingkat sangrai dapat ditingkatkan dengan pendekatan teknologi, antara lain peningkatan suhu sangrai atau peningkatan lama proses sangrai.

Peluang pasar untuk kopi bubuk Desa Permu yang diproduksi oleh kelompok Tik Kerto cukup besar. Hal berdasarkan info tentang beragamnya selera konsumen dan kecendrungan konsumen kopi yang semakin meningkat. Oleh karena itu, maka kualiitas kopi bubuk Desa Permu perlu ditingkatkan dan perizinan perlu dilakukan supaya dapat dipasrkan secara luas. Komoditas kopi bubuk yang dikelola oleh industry rumah tangga adalah dalam bentuk Nomor pangan industry rumah tangga (NO. PIRT) yang dikeluarkan oleh Dinas Kesehatan Kabupaten Kepahiang.

\section{Analisis Fisik Bahan Baku Kopi Bubuk Desa Permu}

Hasil kajian pada kegiatan PPM menunjukkan bahwa rendemen hasil kopi petik merah selektif lebih tinggi dibandingkan kopi hasil petik serabutan. Rendemen hasil kopi petik merah selektif adalah 15,24\% dan rendemen hasil kopi petik serabutan adalah 13,64\%. Hasil tersebut sejalan dengan hasil kajian Alnopri, 
$d k k$., (2013) yang menunjukkan bahwa rendemen hasil kopi petik merah dan lebih tinggi dari hasil petik serabutan. Akan tetapi rendemen bubuk yang dihasilkn jauh lebih rendah dari hasil kajian Alnopri, $d k k$., (2013), yakni sebesar 20,20\%. Hasil ini diduga karena bahan baku kopi biji (green bean) yang digunakan bukan kopi biji hasil petik merah selekti.

Kopi bubuk yang dihasilkan dengan teknologi sangrai tradisional mempunyai rendemen bubuk sebesar 73,33\% dan warna kopi bubuk coklat kehitaman. Alih teknologi dengan menggunakan mesin sangrai dengan antusias dan sangat mudah dikuasai oleh kelompok industri bubuk kopi Tik Kerto Desa Permu. Rendemen bubuk yang dihasilkan adalah $83,10 \%$ dan warna coklat muda. Hasil menunjukkan bahwa teknologi sangrai menggunakan roaster mendapatkan hasil rendemen kopi bubuk lebih tinggi. Hal tersebut disebabkan pengolahan tradisional akan mengakibatkan aroma hilang dan kematangan biji sangrai tidak merata.

Kajian kadar air dan berat jenis kopi sangrai selama proses penyangraian dengan menggunakan mesin roaster disajikan pada Tabel 1.

Tabel 1. Kadar Air dan Berat Jenis Kopi Sangrai

\begin{tabular}{clcc}
\hline No & \multicolumn{1}{c}{ Perlakuan } & Kadar Air $(\%)$ & Berat Jenis $(\mathrm{Gr} / \mathrm{Ml})$ \\
\hline 1 & Kopi beras & 11,63 & 0,4731 \\
2 & Sangrai 60 menit & 7,86 & 0,4348 \\
3 & Sangrai 80 menit & 3,00 & 0,4000 \\
4 & Sangrai 90 menit & 3,00 & 0,3175 \\
5 & Pendinginan 10 menit & 1,99 & 0,3356 \\
\hline
\end{tabular}

Hasil pada Tabel 1 tersebut menunjukkan bahwa kopi bubuk yang dihasilkan oleh kelompok Tik Kerto Desa Permu telah memenuhi SNI 01-3542-2004 berkaitan dengan kriteria kadar air yakni 1,99\% (standar maksimal 7\%) dan keadaan bau, rasa, dan warna pada kriteria normal.

\section{KESIMPULAN DAN SARAN}

\section{Kesimpulan}

1. Kelompok usaha kopi bubuk Desa Permu kecamatan Kepahiang kabupaten Kepahiang sudah mempunyai struktur organisasi yang mempunyai orientasi bisnis dan beranggotakan ibu-ibu yang bernaung pada kelompok "Tik Kerto" ibu-ibu Desa Permu kecamatan Kepahiang kabupaten Kepahiang.

2. Bahan baku industri kopi bubuk berupa kopi biji akan disuplai oleh kebun milik kelompok dan membeli kepada pekebun kopi di kawasan Sengkuang kabupaten Kepahiang. 
3. Bahan baku berupa kopi gelondong basah diolah dengan system kering, dengan jalan menjemur pada tikar jemur dan menumbuk dengan huller.

4. Alih teknologi pengolahan kopi bubuk dari pengolahan tradisonal ke pengolahan menggunakan mesin roaster berlangsung dengan baik.

5. Kualitas kopi bubuk hasil pengolahan menggunakan mesin roaster lebih baik dari pengolahan secara sederhana ditinjau dari rendemen bubuk dan cita rasa kopi.

6. Kopi bubuk Desa Permu telah memenuhi SNI 01-3542-2004 berkaitan dengan kriteria kadar air dan keadaan bau, rasa, dan warna.

7. Pemasaran kopi bubuk Desa Permu dilakukan dengan menitipkan produk pada warung-warung di Desa Permu dan desa-desa sekitarnya.

\section{Saran}

1. Teknologi petik merah secara selektif terus menerus dikampayekan kepada pekebun kopi.

2. Program Pengabdian Pada Masyarakat pada kedua, yakni tahun 2015 diarahkan pada peningkatan kelengkapan sarana produksi kopi bubuk, yakni rumah produksi, mesin pembubu, pengurusan izin usaha (PIRT), dan penguatan pasar.

\section{DAFTAR PUSTAKA}

Alnopri, 2005, Manajemen Usaha Perkebunan, Lembaga Penelitian Universitas Bengkulu, LEMLIT UNIB Press, Bengkulu.

Alnopri, Bandi Hermawan, Sumardi, Prasetyo, dan Yessi Rosalina, 2013, Peningkatan Pendapatan Kelompok Tani Bersaudara Berbasis Intermediate Product di Kabupaten Kaur, Fakultas Pertanian UNIB, Bengkulu.

Alnopri, Prasetyo, dan Yessi Rosalina, 2013, Meraih Nilai Tambah Produk yang Hilang Berbasis Intermediate Product di Desa Permu Kabupaten Kepahiang, LPPM UNIB, Bengkulu.

Badan Standar Nasional, 2004, SNI 01-3542-2004, www.bsn.go.id.

Bappeda Provinsi Bengkulu, 2010, Data Badan Perencanaan Pembanguan Daerah Provinsi Bengkulu, Bengkulu. 
Budiman, H, 2012, Prospek Tinggi Bertanam Kopi, Pedoman Meningkatkan Kualitas Perkebunan Kopi, Seri Pertanian Modern, Penerbit Pustaka Baru Press, Bantul Jogjakarta.

Panggabean, R, 2011, Buku Pintar Kopi, Agro Media Pustaka, Jakarta.

Tim Karya Tani Mandiri, 2010, Pedoman Budidaya Tanaman Kopi, Seri Budidaya Tanaman, CV, Nuansa Aulia, Bandung. 